\title{
French researchers oppose biomedical reform plan
}

[PARIS] Claude Allègre, the French minister for national education, research and technology, has put forward proposals for the reform of the national biomedical research agency, Inserm, aimed at streamlining its administration and increasing its capacity for strategic planning.

But the moves are being viewed with concern by some Inserm researchers, who feel that they would lead to a reduction of their influence over research strategy. More than 200 laboratory heads and other researchers have signed a petition protesting against the proposals for reform of the agency.

One of the main reforms being proposed by Allègre is that there should be a strengthening of the role of the agency's administrative council in making strategic decisions on research directions that have in the past been agreed jointly by the scientific community and Inserm management.

Some scientists have interpreted this as an attempt by the ministry to seek greater control over the agency, and are concerned that the relative lack of scientific experience among members of the new board might lead to a lack of adequate focus in research goals.

Evidence of an apparent desire for greater centralization also comes from plans by the ministry to take direct control of more than half of the funds for laboratory equipment and supplies, which were previously overseen by scientific committees.

At the same time, the ministry proposes to reduce the number of scientists appointed to the agency's elected bodies for evaluating research, while the scientific board will lose its powers for setting research strategies and choosing recruits. Both are being seen as weakening the influence of researchers over broad research strategy.

The fourth major reform outlined is the division of Inserm into scientific departments - similar to the Centre National de la Recherche Scientifique (CNRS) - each of which will be headed by an official appointed by the ministry. The move has surprised scientists as Inserm, with 2,115 scientists and 2,755 technicians, is relatively small compared with CNRS, which has more than 26,000 staff; indeed the whole of Inserm is smaller than the CNRS's life sciences department.

The petition expresses the concern that the moves seem aimed at converting Inserm from an independent research agency with control over its own research activities to a research council distributing funds to university groups and hospitals on the basis of policies defined by the ministry.

The scientists who signed the petition claim that the ministry has failed to consult either Inserm's scientific boards or its trade unions over the planned reforms, describing this as a "dirigiste, centralist, and technocratic" attitude.

This accusation is refuted by the ministry, which claims that Inserm representatives were fully consulted. But Nicolette Farman, from the National Union of Scientific Researchers, says that, while the trade unions were asked for their opinions of the proposed changes, they were excluded from the preparations of the reforms themselves.

In a thinly-veiled attack on the biomedical research agency, the ministry said in a statement that, while its scientific development over the past few years had been globally "positive", it lagged behind in fields such as "instruments, the development of drugs, physiology, clinical trails and medical information", justifying the proposals for reform.

EricGlover

\section{Gould to be next year's president of AAAS}

[WASHINGTON] One of science's best known names, Stephen Jay Gould, has been chosen as the next president-elect of the American Association for the Advancement of Science (AAAS).

Gould, a Harvard University palaeontologist and evolutionary biologist as well as a best-selling author, assumes the post on 18 February, at which time M. R. C. Greenwood, a former associate director of the White House science office and now chancellor of the University of California at Santa Cruz, will become president. Gould will then succeed her in January 1999.

Gould is best known scientifically for his work in developing the theory of punctuated equilibrium, which holds that evolutionary change occurs in sporadic bursts rather than at a steady, gradual pace. He has also written 15 books on science for general readers, and is expected to emphasize public understanding of science during his tenure.

"I want to make people less scared of science so they won't see it as arcane, monolithic and distant, but as something that is important to their lives," Gould said in a statement following the announcement of his election last month.

"We have to ask ourselves why so many people have become so afraid of science - it is no more difficult to learn than other things."

\section{Orbital space debris 'poses main threat to shuttle crew'}

[WASHINGTON] The US government urgently needs to develop an interagency surveillance strategy involving both the Department of Defense (DoD) and the National Aeronautics and Space Administration (NASA) to combat the growing problem of space debris, according to the General Accounting Office (GAO), the investigative arm of Congress.

The recommendation, made in a report published by the GAO last month, coincides with a separate report from the National Research Council (NRC) urging the space agency to boost its efforts to protect the space shuttle from meteoroids and orbital space debris. The council says these now represent "the single greatest threat to the shuttle and its crew" - even higher than the hazards encountered during launch and ascent.

The United States already has a sophisticated Space Surveillance Network, operated by the US Space Command, on which both the DoD and NASA rely for information on objects orbiting the Earth. But the GAO says that this is not capable of providing the information the space agency needs - in terms of both locating and identifying the size of such objects - adequately to predict possible collisions with multibillion-dollar space programmes, such as the international space station.

Although the defence department has plans to modernize its surveillance network radar system and to develop three new ballistic missile warning systems, the GAO says that these plans "do not adequately consider DoD's or NASA's surveillance requirements". Nor does the National Space Policy, published in 1996, make provision for an interagency mechanism to ensure that NASA's requirements are met.

The NRC report was drawn up by a panel set up by its Aeronautics and Space Engineering Board committee to address the potential threat to space shuttle missions posed by orbital debris such as spent rocket bodies, satellite fragments and even paint chips. It points out that NASA's four operating shuttles, which were designed in the 1970s, were not built to repel bombardment by such debris, as it was not recognised at the time to be a substantial threat.

But the growing amount of debris over the past decades, says the committee, has almost doubled the likelihood that the crew might be harmed or that the spacecraft might incur major damage. The committee also points out that more than 95 per cent of the debris that could critically damage the shuttle is too small to be picked up by current groundbased sensors operated by the DoD. 